\title{
Prevalence of Mycobacterium avium in Slaughter Pigs Based on Serological Monitoring Results and Bacteriological Validation
}

\author{
Anne Hiller ${ }^{1,2,3, *, \dagger}$, Derk Oorburg ${ }^{2,3, *, \dagger}$, Henk J. Wisselink ${ }^{4}$, Conny B. van Solt-Smits ${ }^{4}$, \\ Bert Urlings ${ }^{2,3}$, Günter Klein ${ }^{1}$, Gereon Schulze Althoff ${ }^{3}$ and Lourens Heres ${ }^{3}$ \\ 1 University of Veterinary Medicine, Bischofsholer Damm 15, Hannover 30173, Germany; \\ E-Mail: guenter.klein@tiho-hannover.de
}

2 Animal Science Group of Wageningen UR, P.O. Box 338, Wageningen 6700 AH, The Netherlands; E-Mail: bert.urlings@wur.nl

3 VION Food Group, P.O. Box 1, Boxtel 5280 AA, The Netherlands; E-Mails: gereon.schhulze.althoff@vionfood.com (G.S.A.); lourens.heres@vionfood.com (L.H.)

4 Central Veterinary Institute of Wageningen UR, P.O. Box 65, Lelystad 8200 AB, The Netherlands; E-Mails: henk.wisselink@wur.nl (H.J.W.); conny.vansolt@wur.nl (C.B.S.-S.)

$\dagger$ These authors contributed equally to this work.

* Authors to whom correspondence should be addressed; E-Mails: anne.hiller@vionfood.com (A.H.); derk.oorburg@vionfood.com (D.O.); Tel.: +49-211-44033-0 (A.H.); +31-411-658550 (D.O.); Fax: +49-211-44033-569 (A.H.); +31-411-658511 (D.O.).

Received: 11 July 2013; in revised form: 29 July 2013 / Accepted: 19 August 2013 / Published: 30 August 2013

\begin{abstract}
Mycobacterium avium (MA) is a potential food safety hazard in pigs. Blood samples of slaughtered pigs in the Netherlands and Germany were tested for the presence of MA antibodies to estimate the serological prevalence in the tested population. In the Dutch and German population $1.0 \%$ and $1.7 \%$ samples were positive, and $0.5 \%$ and $17.4 \%$ of the herds were at risk for having a MA infection respectively. The validity of the applied MA-ELISA was evaluated under field conditions. The specificity of the MA-ELISA was high $(>98.4 \%)$. The average herd sensitivity was $18 \%$. In the affected herds on average $50 \%$ of the animals were tested bacteriological positive for MA. It can be concluded that serological screening for the presence of MA antibodies is capable of identifying pig populations that are at risk for a MA infection.
\end{abstract}


Keywords: Mycobacterium avium; pig; serology; ELISA; supply chain meat inspection

\section{Introduction}

Mycobacterium avium subsp. avium and M. avium subsp. hominissuis belong to the Mycobacterium avium complex (MAC) and are frequently associated with diseases in animals and humans. MAC is an opportunistic pathogen which leads to disseminated infections with increased morbidity and mortality, particularly in immune-compromised people [1,2]. MAC infections are reported in 30 to $80 \%$ of patients with AIDS [3]. MAC also causes chronic pneumonia in elderly people and cervical lymphadenitis in young children between 0 and 5 years of age $[4,5]$.

Pigs have been suggested as a vector for transmission of MA towards humans [6-8]. The main route of infection in pigs is via the gastro-intestinal tract [9]. Outbreaks in herds are described after feeding pigs with mycobacteria contaminated peat, compost, bark mulch and sawdust [10,11]. In pigs MA can cause lymphadenitis with granulomatous lesions, especially the submaxillary and mesenteric lymph nodes are affected [9]. European law (EU/854/2004) prescribes the procedures for meat inspection, which includes the incision of the submaxillary lymph nodes and palpation of the mesenteric lymph nodes within the meat inspection at slaughter. One of the aims of this legal requirement is the detection of mycobacterial infections in pigs at slaughter.

However, the incision of the lymph nodes is characterized by relatively high false positive and false negative results for MA $[12,13]$. In addition, it can cause cross-contamination with other food safety hazards, e.g., salmonella [14,15]. As an alternative for the lesion criterion, the MA-ELISA test was developed to monitor pig herds serological for MA infections [13].

Starting in 2006 blood samples were collected for monitoring MA infections in slaughter pigs in six Dutch and one German slaughterhouse in the framework of a risk-based meat inspection system [16]. In the present paper the serological prevalence in the tested population was estimated and the tested herds were categorized. Risk categorization was based on an aggregate set of results of the MA-ELISA. The validity of the MA-ELISA test was evaluated under field conditions with samples from MA positive and negative herds.

\section{Experimental Section}

\subsection{Collection of Samples}

At every delivery of a consignment of pigs, blood samples were collected randomly from clinically healthy pigs during bleeding. Samples were identified on a herd level. Treated test tubes $(10 \mathrm{~mL})$ for serum collection with coagulation inducer were used. Until coagulation, samples were stored at room temperature and then up to analyses at $4{ }^{\circ} \mathrm{C}$. The blood was send to one laboratory that carried out the MA-ELISA. In six Dutch slaughterhouses from January 2007 until June 2010 blood serum samples were taken from 248,325 pigs delivered by 4,830 herds and examined for MA antibodies. In the German slaughterhouse blood serum samples were taken from 57,044 pigs delivered by 1,249 herds from October 2008 until April 2010. 


\subsection{Applied ELISA and Herd Categorization}

Development on the basis of a polar lipid fraction from MA, characteristics of the MA-ELISA and its procedures have been previously described by Wisselink et al. [13]. The MA-ELISA test results were calculated as percentage positivity (PP). A cut-off value of PP 20 was used. Herds with two or more positive samples out of 36 samples, achieved over at least 12 batches, were considered at risk for MAA.

\subsection{MA-ELISA Validation}

For the validation of the MA-ELISA and the pathological examination of the submaxillary lymph nodes the bacteriological MA examination of the submaxillary and mesenteric lymph nodes was used as the gold standard.

\subsubsection{Evaluation of Sensitivity under Field Conditions}

To evaluate the MA-ELISA under field conditions, pig herds $(n=11)$ with a high number of positive serum samples and/or granulomatous lymph nodes at meat inspection were pre-selected. To confirm the MA infection status on these farms, fattening pigs ( $n=22-68$ per herd) which were nearly ready for slaughter were subjected to an intradermal tuberculin test into the base of the ear with $0.1 \mathrm{~mL}$ Avian Tuberculin PPD (25.000 I.U., ASG, Lelystad, The Netherlands). Evaluation occurred after 36 to $72 \mathrm{~h}$ by checking the injection site for signs of induration and erythema. Herds were selected for sample collection when pigs reacted positive in the tuberculin skin test. From these herds blood serum samples and the submaxillary and mesenteric lymph nodes were collected at slaughter. In the laboratory, serum samples were stored at $-20{ }^{\circ} \mathrm{C}$ until serological analysis and the submaxillary lymph nodes were examined pathologically for caseous malformations and the submaxillary and mesenteric lymph nodes were bacteriologically examined for MA, as described by Wisselink et al. [13]. For bacteriological examination Middlebrook $7 \mathrm{H} 10$ plates enriched with OADC on Coletsos Osein and on Dubos Tween albumin medium were used. Ziehl-Neelson stain and PCRs were performed to identify colonies.

\subsubsection{Evaluation of Specificity under Field Conditions}

For evaluation of the specificity of the MA-ELISA under field conditions, pig herds $(n=8)$ with only negative serological samples for MA were selected. From 239 pigs blood samples and the submaxillary and mesenteric lymph nodes were collected at slaughter and examined as described above.

\subsubsection{Herd Sensitivity Calculations}

A distinction was made between the sensitivity of an individual test, further called carcass sensitivity and the herd sensitivity when the MA-ELISA was used as a herd diagnostic test. The sensitivity as herd diagnostic test was calculated. Herd sensitivity was defined as the probability that a positive herd is diagnosed positive following the evaluation of an aggregated set of serum samples (in this case 36 samples). The herd sensitivity is the probability that the number of positive samples from positive herds is equal to or above a minimum needed number of positive serum samples, here it is calculated for one and two positive samples, where the latest is used in the system. 
The probability that from a set of 36 serum samples $<1$ or $<2$ serum samples are positive can be calculated with the cumulative distribution function of the binomial distribution, Equation (1):

$$
F(x ; n, p)=\operatorname{Pr}(X \leq x)=\sum_{i=0}^{x}\left(\begin{array}{l}
n \\
i
\end{array}\right) p^{i}(1-p)^{n-i}
$$

In that case $n=36$ and $\mathrm{x}$ is respectively 0 and 1 . The apparent prevalence in the population (p) is the real prevalence in the population multiplied with the individual carcass sensitivity. The herd sensitivity (Sensherd) is the probability that out of the 36 samples more than one respectively two samples are positive:

$$
\text { Sensherd }_{\text {he }}=1-\operatorname{Pr}(\mathrm{X} \leq \mathrm{x})
$$

The herd sensitivity was calculated for a range of carcass sensitivities at a range of carcass prevalences as observed in the different validation trials.

\subsubsection{Herd Specificity Calculations}

A distinction was made between the specificity of an individual test, further called carcass specificity and the herd specificity when the MA-ELISA was used as a herd diagnostic test. Herd specificity ( Spec $_{\text {herd }}$ ) was calculated in the same way. Herd specificity is one minus the probability that there are two or more false positive test results out of 36 samples calculated with the cumulative distribution function, where probability of a false positive test result is one minus the carcass specificity.

\subsubsection{Statistics}

To test the statistical significance of differences in proportion of positive samples a Chi square test was done.

\section{Results and Discussion}

\subsection{Results}

3.1.1. Serological MA-Monitoring in the German and Dutch Slaughterhouse(s) and Herd Risk Categorization

In six Dutch slaughterhouses 248,325 blood serum samples were taken from 4,830 herds and examined for MA antibodies. The results showed that 2,495 (1.0\%) serum samples had a positive result in the MA-ELISA (Figure 1). From 4,817 pig herds, at least 36 samples were collected during this period. Twenty five $(0.5 \%)$ of these herds had two or more positive samples out of 36 .

In the German slaughterhouse blood serum samples were taken from 57,044 pigs delivered by 1,249 herds. From these serum samples $984(1.7 \%)$ had a positive result. From 574 herds, at least 36 samples were collected during this period. One hundred of these herds $(17.4 \%)$ had two or more positive samples out of 36 . 
Figure 1. Proportion of MA-ELISA positive serum samples in relation to the number of tested serum samples in The Netherlands (A) and in Germany (B) in the period 2008-2010.

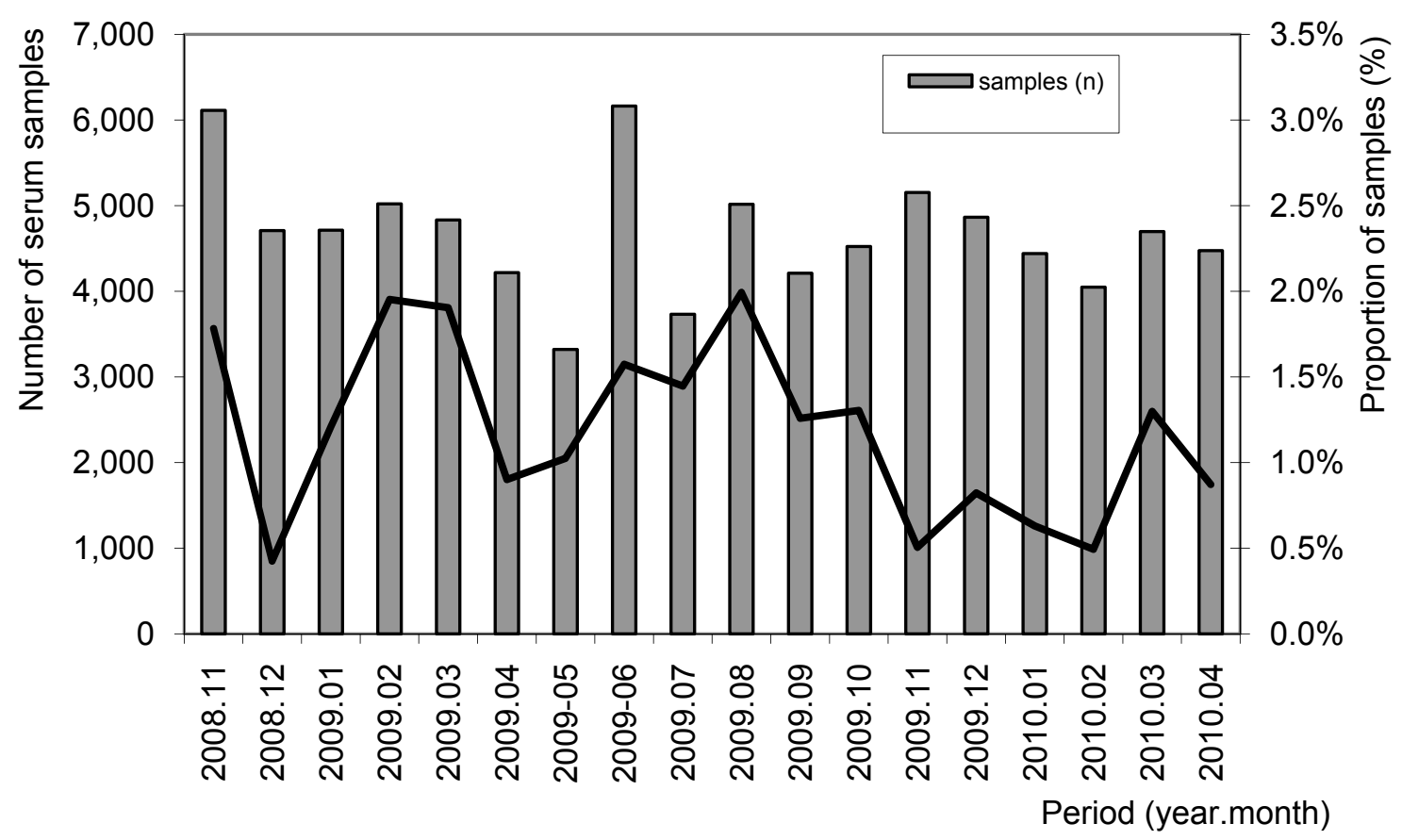

(A)

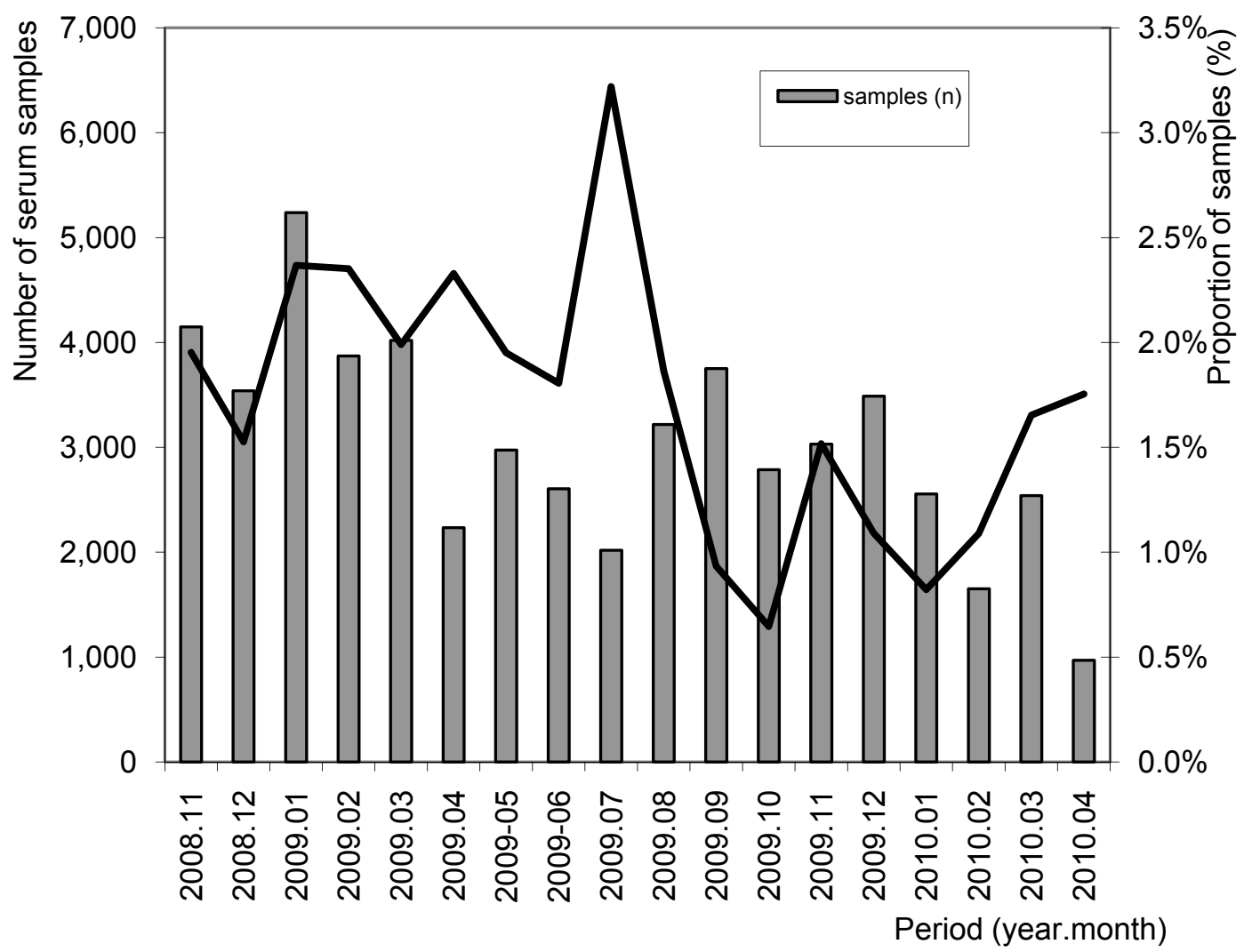

(B) 
The proportion of positive samples in the different months is shown in Figure 1. The proportion of positive samples $(1.7 \%$ versus $1.0 \%)$ and herds $(17.4 \%$ versus $0.5 \%)$ were significantly higher in the tested German population compared to the tested Dutch pigs (Chi-square; $p<0.05$ ).

\subsubsection{Evaluation of Sensitivity under Field Conditions}

In four of the eleven serologically identified MA farms, pigs were detected with a positive tuberculin skin test. Additional blood and lymph nodes were sampled on pigs from these four tuberculination positive herds (farm A: Netherlands, farm B: Belgium, farm D, E: Germany) and examined for M. avium Infections.

The results showed that the proportion of the MA-ELISA positive samples at the four farms varied between $3.4 \%$ and $11 \%$. The carcass sensitivity (sensitivity of an individual test) based on bacteriological examination of the lymph nodes varied between $2.4 \%$ and $16.7 \%$ (Table 1). The average proportion of granulomatous lesions detected by pathological examination in the submaxillary lymph nodes was $22.5 \%$ ( 85 of 378). The lowest proportion of lesions was $8 \%$ (9 of 117) (farm B) and the maximum was 31\% (57 of 184) (farm A). The carcass sensitivity (sensitivity of an individual test) of the pathological examination under laboratory conditions varied between $19.5 \%$ and $67 \%$ and on average it was $32.6 \%$. Results of bacteriological examination of the submaxillary and mesenteric lymph nodes showed that on average 50\% (188 of 375) of the pigs were infected with M. avium hominisuis (MAH) (Table 1), the minimum level of infection with MAH was 32\% (6 of 19) (farm E) and the maximum level was 66\% (38 of 55) (farm D).

Table 1. Test characteristics of the applied MA-ELISA validated with animals from four positive farms.

\begin{tabular}{cccccccccc}
\hline \multirow{2}{*}{$\begin{array}{c}\text { Farm } \\
\text { (Country) }\end{array}$} & $\begin{array}{c}\text { Bacteriology } \\
\text { +ve/n (\%) }\end{array}$ & \multicolumn{3}{c}{ Pathology $^{2}$} & \multicolumn{5}{c}{ Serology (PP $>20)$} \\
\cline { 3 - 9 } & + +ve/n (\%) & Se\% & Sp\% & + ve/n (\%) & $\begin{array}{c}\text { Se\% } \\
\text { (carcass) }\end{array}$ & Sp\% & PPV\% & NPV\% \\
\hline $\mathrm{A}^{3}(\mathrm{NL})$ & $103 / 184(56)$ & $57 / 184(31)$ & 35.0 & 74.1 & $8 / 184(4.3)$ & 4.9 & 96.3 & 62.5 & 44.3 \\
$\mathrm{~B}^{3}(\mathrm{~B})$ & $41 / 117(35)$ & $9 / 117(8)$ & 19.5 & 98.7 & $4 / 117(3.4)$ & 2.4 & 96.1 & 25.0 & 64.6 \\
$\mathrm{D}^{4}(\mathrm{GE})$ & $38 / 55(66)$ & $16 / 58(28)$ & 40.5 & 94.4 & $3 / 55(5.5)$ & 2.7 & 88.9 & 33.3 & 30.7 \\
$\mathrm{E}^{4}(\mathrm{GE})$ & $6 / 19(32)$ & $3 / 19(16)$ & 66.7 & 92.3 & $2 / 19(11)$ & 16.7 & 92.3 & 50.0 & 70.1 \\
TOTAL (\%) & $188 / 375(50)$ & $85 / 378(23)$ & 32.6 & 87.2 & $17 / 375(4.5)$ & 4.3 & 95.2 & 49.4 & 50.0 \\
\hline
\end{tabular}

${ }^{1}$ Positive when M. avium bacteria were detected by bacteriological examination on submaxillary lymph nodes and/ or mesenteric lymph nodes; ${ }^{2}$ Positive when granulomatous lesions were seen in the submaxillary lymph nodes during pathological examination in laboratory; ${ }^{3}$ Partly published by Wisselink et al. [13]; ${ }^{4}$ Partly published by Hiller et al. [17] Se = carcass Sensitivity, Sp = carcass Specificity. PPV = Positive Predictive Value, NPV $=$ Negative Predictive Value, +ve $=$ positive, $n=$ number of tested samples $\mathrm{B}=$ Belgium, $\mathrm{GE}=$ Germany, $\mathrm{NL}=$ The Netherlands.

\subsubsection{Evaluation of the Carcass Specificity of the MA-ELISA under Field Conditions}

From 239 pigs from low MA risk herds the submaxillary and mesenteric lymph nodes were bacteriologically negative for MA. Carcass specificity (specificity of an individual test) of the MA-ELISA at a cut-off of PP 20 was 100\% (95\% CI: 98.4\%-100\%). The carcass specificity of the pathological examination under laboratory conditions was $97 \%$ (Table 2). 
Table 2. Results of serological, pathological and bacteriological examinations for M. avium infections on farms categorised at "low" risk for a M. avium infection.

\begin{tabular}{|c|c|c|c|c|c|c|c|c|}
\hline \multirow{3}{*}{$\begin{array}{l}\text { Pig } \\
\text { farm }\end{array}$} & \multirow{3}{*}{$\begin{array}{c}\text { Number of } \\
\text { pigs sampled }\end{array}$} & \multirow{3}{*}{$\begin{array}{c}\text { Serology } \\
\text { PP }>20\end{array}$} & \multicolumn{3}{|c|}{ Lnn. mandibulares } & \multicolumn{3}{|c|}{ Lnn. mesenteriales } \\
\hline & & & \multicolumn{2}{|c|}{ Pathology ${ }^{1}$} & \multirow{2}{*}{$\begin{array}{c}\text { Bacteriology }^{2} \\
+ \text { ve }\end{array}$} & \multicolumn{2}{|c|}{ Pathology } & \multirow{2}{*}{$\begin{array}{c}\text { Bacteriology } \\
+ \text { ve }\end{array}$} \\
\hline & & & $-\mathbf{v e}$ & $+v e$ & & $-\mathbf{v e}$ & $+\mathbf{e}$ & \\
\hline 116 & 3 & 0 & 3 & 0 & 0 & 3 & 0 & 0 \\
\hline 724 & 10 & 0 & 10 & 0 & 0 & 10 & 0 & 0 \\
\hline 736 & 10 & 0 & 10 & 0 & 0 & 8 & 2 & 0 \\
\hline 875 & 33 & 0 & 31 & 2 & 0 & 33 & 0 & 0 \\
\hline 907 & 41 & 0 & 38 & 3 & 0 & 39 & 2 & 0 \\
\hline 826 & 39 & 0 & 36 & 1 & 0 & 31 & 0 & 0 \\
\hline 014 & 33 & 0 & 32 & 0 & 0 & 24 & 2 & 0 \\
\hline 088 & 71 & 0 & 70 & 1 & 0 & 45 & 0 & 0 \\
\hline $\begin{array}{l}\text { Total } \\
(\%)\end{array}$ & 239 & 0 & 230 & $\begin{array}{c}7 \\
(3.0 \%) \\
\end{array}$ & 0 & 193 & $\begin{array}{c}6 \\
(3.1 \%) \\
\end{array}$ & 0 \\
\hline Sp & & $100 \%$ & & $97 \%$ & & & $96.9 \%$ & \\
\hline
\end{tabular}

1 Positive when granulomatous lesions were seen in the submaxillary lymph nodes during pathological examination. ${ }^{2}$ Positive when $M$. avium bacteria were detected by bacteriological examination on submaxillary lymph nodes and/ or mesenteric lymph nodes; $-\mathrm{ve}=$ negative, + ve $=$ positive, $\mathrm{Sp}=$ Specificity.

\subsubsection{Herd Sensitivity Calculations}

When the observed range of MA-ELISA carcass sensitivities $(2.4 \%-16.7 \%)$ and the observed range for bacteriological carcass prevalence of MA bacteria at herd level $(32 \%-66 \%)$ were applied for herd sensitivity calculations, the probability to have at least one positive serological sample varies between $23 \%$ and $100 \%$ (Table 3). This is the probability that positive herds were recognized with the serological test.

With the average carcass sensitivity of $4.3 \%$ and $50 \%$ bacteriological positive animals in the affected herds the probability of one positive sample in an affected herd was $54 \%$. The probability to obtain two or more serum samples positive was 3\%-97\%, depending on the bacteriological prevalence (Table 3). This is the probability for a herd to become categorised as "at risk". With the average carcass sensitivity of $4.3 \%$ and $50 \%$ bacteriological positive animals in the affected herds the herd sensitivity was $18 \%$.

\subsubsection{Herd Specificity Calculations}

Calculations of the apparent herd prevalence (AHP) showed that when the test systematic has a herd sensitivity of $20 \%$ and herd specificity of $98.5 \%$ the AHP will not be below $1.5 \%$. These were false positives resulting from the $98.5 \%$ herd specificity, based on an assumed carcass specificity of $99.5 \%$. In the Dutch population only $0.5 \%$ "at risk" farms were detected. Therefor the herd specificity of the test systematic was higher than $98.5 \%$. This also means that the carcass specificity for an individual test was higher than $99.5 \%$. 
Table 3. Herd sensitivity of the MA-ELISA in a range of observed carcass sensitivities and bacteriological prevalences of $M$. avium at 1 or more and 2 or more positive samples for a positive herd diagnosis.

\begin{tabular}{|c|c|c|c|c|c|}
\hline \multirow{3}{*}{$\begin{array}{c}\text { Within-herd } \\
\text { bacteriological } \\
\text { prevalence of } M \text {. avium }\end{array}$} & \multicolumn{5}{|c|}{ MA-ELISA carcass sensitivity } \\
\hline & 2.4 & $5 \%$ & $10 \%$ & $16.7 \%$ & $20 \%$ \\
\hline & \multicolumn{5}{|c|}{ probability $\geq 1$ out of 36 positive blood serum samples } \\
\hline $30 \%$ & $23 \%$ & $42 \%$ & $67 \%$ & $84 \%$ & $89 \%$ \\
\hline $40 \%$ & $29 \%$ & $52 \%$ & $77 \%$ & $92 \%$ & $95 \%$ \\
\hline $50 \%$ & $35 \%$ & $60 \%$ & $84 \%$ & $96 \%$ & $98 \%$ \\
\hline $60 \%$ & $41 \%$ & $67 \%$ & $89 \%$ & $98 \%$ & $99 \%$ \\
\hline \multirow[t]{2}{*}{$70 \%$} & $46 \%$ & $73 \%$ & $93 \%$ & $99 \%$ & $100 \%$ \\
\hline & \multicolumn{5}{|c|}{ probability $\geq 2$ out of 36 positive blood serum samples } \\
\hline $30 \%$ & $3 \%$ & $10 \%$ & $29 \%$ & $54 \%$ & $64 \%$ \\
\hline $40 \%$ & $5 \%$ & $16 \%$ & $42 \%$ & $70 \%$ & $79 \%$ \\
\hline $50 \%$ & $7 \%$ & $23 \%$ & $54 \%$ & $81 \%$ & $89 \%$ \\
\hline $60 \%$ & $9 \%$ & $29 \%$ & $64 \%$ & $89 \%$ & $94 \%$ \\
\hline $70 \%$ & $12 \%$ & $36 \%$ & $73 \%$ & $93 \%$ & $97 \%$ \\
\hline
\end{tabular}

\subsection{Discussion}

M. avium subsp. avium and M. avium subsp. hominissuis are relevant food safety risks in pigs [6-8]. With the present MA-ELISA detection of MA risk herds can be done much easier than by the classical incision of lymph nodes in the traditional meat inspection. Infections of the lymph nodes are detected by inspection of the submaxillary lymph nodes after incision within the traditional meat inspection in pigs. A recent review showed that during meat inspection in Germany malformations were detected in only $0.22 \%$ of slaughtered pig carcasses (Federal Statistical Office of Germany, 2007; according to $\mathrm{BfR}$ report). Caseous malformations in porcine lymph nodes and sometimes in kidneys, liver and spleen can be caused by mycobacteria $[9,18,19]$, but most of them originate from Rhodococcus equi infections [12,20,21]. On the other hand, other studies showed that lymph nodes without any lesions can harbour MA [20,22]. Henceforth, the incision of submaxillary lymph nodes in the traditional meat inspection appears to be a non-sensitive and a non-specific test.

In the present study a serological screening for MA infections as alternative method was tested to identify MA positive herds at slaughter. The number of MA positive carcasses was $1.01 \%$ and $1.73 \%$ in respectively the Dutch and German pig population. These proportions of positive carcasses are comparable to the prevalence of granulomatous malformations in lymph nodes seen at pathological examination, $1.85 \%$ by Fischer [23], $0.89 \%$ by Meyer et al. [24] and $0.48 \%$ by Lücker et al. [25] of which about one third showed to be bacteriological positive for MA.

The results of the present study show, that serological screening for MA infections has the capacity to identify bacteriological MA positive herds. Screening results showed that $0.5 \%$ of the Dutch herds and $17.4 \%$ of the German herds had two or more positive samples out of 36 analysed blood samples. These figures also show that MA infection in pigs occurs at a low level. Additionally they show that the prevalence of MA infections differs across populations. There was a higher level of positive samples and herds in the German population compared to the Dutch. As recent studies show [10,11], 
peat, that is usually used as a feed supplement may be contaminated with MA. In German breeder herds peat is more frequently supplied than in Dutch ones (data not shown) which possibly explains the differences.

The applied MA-ELISA was validated on tuberculation-confirmed MA positive farms. The validation results showed, that the sensitivity of an individual test was low, i.e., varying sensitivities were found with an average of $4.3 \%$. Nevertheless, it was shown that approximately $20 \%$ of bacteriologically positive herds can be identified when 36 blood samples are tested and at least two samples need to be positive above PP 20 in the ELISA. An improvement of the MA-ELISA test sensitivity seems achievable, as in experimentally infected pigs [13] and in some of the field farms these higher sensitivities were observed. The low average sensitivity might be due to presence of infections with other MA serotypes [26] that have insufficient cross-immunity toward the antigens used in the test. Additional antigens could be added to the MA-ELISA test to improve its performance.

Besides the fact that screening in pig blood collected at slaughter can efficiently be done, there are important advantages of omitting incision of the lymph nodes within meat inspection. Firstly, cross contamination of salmonella due to incision is prevented [15,27]. Secondly, in the supply chain meat inspection system, where this serology is used to categorise herds, much more effort is done to control MA with increased biosecurity standards and follow-up at high risk farms [17]. This prevention of infection with MA in swine at farm level has not been an active constituent in the traditional meat inspection, which is an end of line check only.

\section{Conclusions}

It can be concluded that a population-wide screening for the presence of MA antibodies is capable of identifying pig populations that are at higher risk for MA infection. The validation results of the applied ELISA indicate that positive farms will not in all cases be identified at first instance. However, on the farms that are identified, MA is actively prevented from entering the food chain. Positive MA test results can be reported back to the pig producers and, additionally, control measures and corrective actions can take place at farm level. In this way the overall prevalence in the supplying herds will be reduced. Moreover, abolishment of incision of the lymph nodes prevents cross contamination with salmonella, improving food safety level.

\section{Acknowledgments}

Special thanks go to Marion Tieman (Central Veterinary Institute of Wageningen UR) who tested the blood samples in the MA-ELISA. The research leading to these results has received funding from the Dutch ministry of Economic affairs with an innovation grant IS055030, the European community's Seventh Framework Programme FP7/2007-2013 under grant agreement $n^{\circ} 228821$ and the Central marketing organisation of the German agrarian economy $\mathrm{mbH}$.

\section{Conflicts of Interest}

The authors declare no conflict of interest. 


\section{References}

1. Ashford, D.A.; Whitney, E.; Raghunathan, P.; Cosivi, O. Epidemiology of selected mycobacteria that infect humans and other animals. Rev. Sci. Tech. 2001, 20, 325-337.

2. Falkinham, J.O. Epidemiology of infection by nontuberculous mycobacteria. Clin. Microbiol. Rev. 1996, 9, 177-215.

3. Bermudez, L.E.; Petrofsky, M.; Kolonosi, P. An animal model of Mycobacterium avium complex disseminated infection after colonization of the intestinal tract. J. Infect. Dis. 1992, 165, 75-79.

4. Eriksson, M.; Bennet, R.; Danielsson, N. Non-tuberculous mycobacterial lymphadenitis in healthy children: Another "lifestyle disease"? Acta Paedriatica 2001, 90, 1340-1342.

5. Nylen, O.; Berg-Kelly, K.; Andersson, B. Cervical lymph node infections with non-tuberculous mycobacteria in preschool children: Interferon gamma deficiency as a possible cause of clinical infection. Acta Paedriatica 2000, 89, 1322-1325.

6. Komijn, R.E.; de Haas, P.E.; Schneider, M.M.; Eger, T.; Nieuwenhuijs, J.H.; van den Hoek, R.J.; Bakker, D.; van Zijderveld, F.G.; van Soolingen, D. Prevalence of Mycobacterium avium in slaughter pigs in The Netherlands and comparison of IS1245 restriction fragment length polymorphism patterns of porcine and human isolates. J. Clin. Microbiol. 1999, 37, 1254-1259.

7. Martin, G.; Schimmel, D. Die Mycobacterium avium - Infektion des Geflügels-(k)eine Gefahr für die menschliche Gesundheit? (Article in German). Deutsche Tierärztliche Wochenschrift 2000, $107,53-58$.

8. Möbius, P.; Lentzsch, P.; Moser, J.; Naumann, L.; Martin, G.; Kohler, H. Comparative macrorestriction and RFLP analysis of Mycobacterium avium subsp. avium and Mycobacterium avium subsp. hominissuis isolates from man, pig, and cattle. Vet. Microbiol. 2006, 117, 284-291.

9. Thoen, C.O. Tuberculosis. In Diseases of Swine, 9th ed.; Straw B.E., Zimmermann J.J., D’Allaire, S., Taylor, D.J., Eds.; Blackwell Publishing: Iowa, IA, USA, 2006; pp. 807-822.

10. Matlova, L.; Dvorska, L.; Ayele, W.Y.; Bartos, M.; Amemori, T.; Pavlik, J. Distribution of Mycobacterium avium complex isolates in tissue samples of pigs fed peat naturally contaminated with mycobacteria as a supplement. J. Clin. Microbiol. 2005, 43, 1261-1268.

11. Trckova, M.; Hudcova, H.; Faldyna, M.; Zraly, Z.; Dvorska, L.; Beran, V.; Pavlik, J. Peat as a feed supplement for animals: A review. Vet. Med. 2005, 50, 361-377.

12. Komijn, R.E.; Wisselink, H.J.; Rijsman, V.M.; Stockhofe-Zurwieden, N.; Bakker, D.; van Zijderveld, F.G.; Eger, T.; Wagenaar, J.A.; Putirulan, F.F.; Urlings, B.A. Granulomatous lesions in lymph nodes of slaughter pigs bacteriologically negative for Mycobacterium avium subsp. avium and positive for Rhodococcus equi. Vet. Microbiol. 2007, 120, 352-357.

13. Wisselink, H.J.; van Solt-Smits, C.B.; Oorburg, D.; van Soolingen, D.; Overduin, P.; Maneschijn-Bonsing, J.; Stockhofe-Zurwieden, N.; Buys-Bergen, H.; Engel, B.; Urlings, B.A.; et al. Serodiagnosis of Mycobacterium avium infections in pigs. Vet. Microbiol. 2010, 142, 401-407.

14. Hamilton, D.R.; Lyall, L.; Lester, S.; McOrist, S.; Hathaway, S.C.; Pointon, A.M. Risk-based evaluation of post-mortem inspection procedures for pigs in Australia. Vet. Record 2002, 151, $110-116$. 
15. SCVMPH. Opinion of the Scientific Committee on Veterinary Measures Relating to Public Health on Revision of Meat Inspection Procedures. 2000. Available online: http://ec.europa.eu/food/fs/sc/scv/out30_en.pdf) (accessed on 24 February 2000).

16. Hiller, A.; Heres, L.; Schulze Althoff, G.; Urlings, B.; Klein, G. Implementierung einer risikoorientierten Fleischuntersuchung ohne Anschnitte beim Mastschwein in einem norddeutschen Schlachtunternehmen. Archiv. Für. Lebensmittelhygiene 2012, 63, 107-114.

17. Hiller, A.; Wisselink, H.J.; van Solt-Smits, C.B.; Oorburg, D.; Schulze Althoff, G.; Klein, G. Confirmation of the Presence of Mycobacterium avium Infections in two Pig Herds which had a High Risk Profile for M. avium as Assessed by Serologically Monitoring. In Proceedings of the 21st International Pig Veterinary Society Congress, Vancouver, Canada, 18-21 July 2010; D’Allaire, S., Friendship, R., Eds.; IPVS 2010 Congress Secretariat: Vancouver, Canada, 2010; p. 674,980 .

18. Offermann, U.; Bodmer, T.; Audigé, L.; Jemmi, T. The prevalence of salmonella, yersinia and mycobacteria in slaughtered pigs in Switzerland. Schweiz. Archiv. Für. Tierheilkunde 1999, 141, 509-515.

19. Van Ingen, J.; Wisselink, H.J.; van Solt-Smits, C.B.; Boeree, M.J.; van Soolingen, D. Isolation of mycobacteria other than Mycobacterium avium from porcine lymph nodes. Vet. Microbiol. 2010, 144, 250-253.

20. Dvorska, L.; Parmova, M.; Lavickova, M.; Bartl, J.; Vrbas, V.; Pavlik, J. Isolation of Rhodococcus equi and atypical mycobacteria from lymph nodes of pigs and cattle in herds with the occurrence of tuberculoid gross changes in the Czech Republic over the period 1996-1998. Vet. Med. 1999, 44, 321-330.

21. Pate, M.; Zdovc, I.; Pirs, T.; Krt, B.; Ocepek, M. Isolation and characterisation of Mycobacterium avium and Rhodococcus equi from granulomatous lesions of swine lymph nodes in Slovenia. Acta Vet. Ungaricae 2004, 52, 143-150.

22. Brown, J.; Neuman, M.A. Lesions of swine lymph nodes as a diagnostic test to determine mycobacterial infection. Appl. Environ. Microbiol. 1979, 37, 740-743.

23. Fischer, S. Epidemiologische Untersuchungen zur Bedeutung von Mykobakterieninfektionen bei Schlachtschweinen unter besonderer Berücksichtigung des Mycobacterium avium-intracellulareKomplexes (Dissertation in German). Universität Leipzig; Leipzig, Deutschland, 1999.

24. Meyer, S.; Großpietsch, R.; Oetjen, M.; Borgmann-Fuchs, D.; Fries, R. Prävalenz und Prädilektionsstellen von Mykobakterien des MAIC beim Schlachtschwein (Article in German), In 7 Fachtagung Fleisch- und Geflügelfleischhygiene für Angehörige der Veterinärverwaltung Berlin, Eigenverlag, Berlin, Germany. 2007. pp. 65-73. Available online: http:/edocs.fuberlin.de/docs/servlets/MCRFileNodeServlet/FUDOCS_derivate_000000001061/Uni-Bibliographie_ 27 2007.pdf?hosts= (accessed on 27 August 2013).

25. Lücker, E.; Thorius-Ehler, S.; Zschöck, M.; Bülte, M. Zur Frage der Fleischhygienerechtlichen Beurteilung Tuberkulöser Veränderungen (Article in German). In Proceedings of the 38 Arbeitstagung des Arbeitsgebietes Lebensmittelhygiene“ der Deutschen Veterinärmedizinischen Gesellschaft e.V. Garmisch-Partenkirchen, Germany, 1997; pp. 502-508. 
26. Dvorska, L.; Matlova, L.; Bartos, M.; Parmova, D.; Bartl, J.; Svastova, P.; Bull, T.J.; Pavlik, I. Study of Mycobacterium avium complex strains isolated from cattle in the Czech Republic between 1996 and 2000. Vet. Microbiol. 2004, 99, 239-250.

27. Peel, B.; Simmons, G.C. Factors in the spead of salmonella in meat works with special reference to contamination of knives. Aust. Vet. J. 1978, 54, 106-110.

(C) 2013 by the authors; licensee MDPI, Basel, Switzerland. This article is an open access article distributed under the terms and conditions of the Creative Commons Attribution license (http://creativecommons.org/licenses/by/3.0/). 